\title{
Uniaxial Transformation Behavior in Tension and Compression in an Fe-Based Shape Memory Alloy: Transformation Lines and Thermomechanical Hystereses
}

\author{
F. Nishimura, N. Watanabe and K. Tanaka \\ Department of Aerospace Engineering, Tokyo Metropolitan Institute of Technology, Asahigaoka 6-6, \\ J-191 Hino/Tokyo, Japan
}

\begin{abstract}
The uniaxial thermomechanical behavior of a polycrystalline $\mathrm{Fe}-9 \% \mathrm{Cr}-5 \% \mathrm{Ni}-14 \% \mathrm{Mn}-6 \% \mathrm{Si}$ (all wt.\%) shape memory alloy is investigated for both tensile and compressive stress states. The martensite start stresses measured upon tension and compression loading of austenite depend linearly on temperature, thus forming straight lines in the stress-temperature regime. The lines belonging to tension and compression are not symmetric with respect to zero stress. The austenite start and finish temperatures measured upon heating under external stress, on samples which had previously been strained by inducing martensite, vary linearly with the stress level applied, thus forming the so-called austenite start and finish lines. The temperature difference (retransformation range) between the austenite start and finish lines increases with increasing amount of previously induced strain/martensite, but the slopes of these lines remain the same. At the minimum amount of previously induced strain/martensite the start and finish lines coincide and are called initial austenite lines. The austenite start and finish lines obtained after previous tensile straining extend to the compression side without change of slope, while the austenite lines obtained after previous compression straining extend to the tensile side without change of slope. The determined transformation lines provide a good means to explain the thermomechanical response of the alloy, i.e., the stress-strain-temperature hysteresis loops.
\end{abstract}

\section{INTRODUCTION}

The transformations in shape memory alloys are induced both by the applied load and the temperature. It is, therefore, very natural to expect that, just like the yield condition in plasticity, a transformation condition governs the start and progress of the transformations at a material point in the alloys [1-4]. As in the case of plasticity the transformation condition can be depicted as a closed surface in the stress-temperature space, which deforms and moves in the space as the transformation progresses [5].

The transformation start condition, which is nothing other than a section of the above-mentioned transformation surface on the stress-temperature plane, has since long been investigated in shape memory alloys as a transformation diagram in the case of the transformations among the phases [6] and as the transformation start/finish lines in the simple case of the martensitic/reverse transformation between the parent phase and the martensite phase [7-11]. The twinning and detwinning zones have also been discussed on the stress-temperature plane as the condition which governs the twin boundary movement in the variants $[12,13]$. Quite different data have been reported on the transformation start/finish condition in TiNi [8,14], Cu-Zn-Al [15-18], Cu-Al-Mn [16], Fe-Mn-Si [18] and Fe-Mn-Si-Cr-Ni-Co [19] alloys. Sun and Hwang [1] have constructed a macroscopic transformation condition of shape memory alloys from the microscopic response of the alloys, whereas Patoor et al. [2] have shown, from the micromechanical investigation on the twin boundary movement in the variants, that the transformation surface in a single crystal is represented by a Prager type surface in the stress space, being different from a von Mises type ellipsoid familiar in plasticity. The transformation condition different from the von Mises criterion is supported by the extensive tension-torsion tests in a Cu-based alloy by Sittner and Tokuda [20,21].

The transformation lines of the Fe-based alloy studied here, Fe-9\% Cr-5\% Ni-14\% Mn-6\% Si (all wt.\%) polycrystalline shape memory alloy, have been reported by the present authors in the tensile stress state [710]. Before drawing a full transformation surface in the 3D stress-temperature space, the transformation lines are determined here both in the tensile and the compressive stress states. The stress-strain-temperature hysteresis loops are also studied under static and cyclic thermomechanical loading [22,23].

\section{ALLOY AND EXPERIMENTAL PROCEDURE}

The alloy tested in the present study, Fe-9\% Cr-5\%Ni-14\%Mn-6\%Si polycrystalline shape memory alloy, was prepared by vacuum induction melting. The test specimens, $6 \mathrm{~mm}$ in diameter with $20 \mathrm{~mm}$ gauge 
length, were machined from the hot-rolled plate which had been homogenized at $1323 \mathrm{~K}$ for $3.6 \mathrm{Ks}$. The specimen axis is parallel to the transverse direction of the plate.

Tests were carried out with a servo-hydraulic thermal fatigue testing machine equipped with a high-frequency induction heater. The displacement was measured with a differential transformer, whereas the temperature of the specimen was detected with a platinum/platinum-rhodium thermocouple spot-welded at the center in the gauge length.

The following training was carried out four times prior to the tests: The specimen was mechanically loaded to $4 \%$ at RT (room temperature, $303 \mathrm{~K}$ ) and unloaded. Heating to $873 \mathrm{~K}$, holding for $600 \mathrm{~s}$, and successive cooling to RT then followed. To cancel the cyclic effect, the specimens were subjected to an additional thermomechanical training before each test, being composed of an isothermal loading up to 350 $\mathrm{MPa}$ at RT and the subsequent heating under free-stress to complete the reverse transformation. 30 cycles of this training were enough to exhibit a stable thermomechanical response with a full recovery.

The thermomechanical load path in Fig.1 is composed of an isothermal mechanical branch, loading/unloading between the lower limit stress $\sigma_{\mathrm{h}}$ and the upper limit stress $\sigma_{\max }$ at a hold temperature $T_{h}$, and $a$ subsequent thermal branch, heating/cooling between the lower limit temperature $T_{h}$ and the upper limit temperature $T_{\max }$ under a hold stress $\sigma_{\mathrm{h}}$. The martensite start stress $\sigma_{\mathrm{Ms}}$ was measured from the stress-strain output during mechanical loading as a $0.05 \%$ proof stress, whereas the austenite start temperature $T_{\mathrm{As}}$ and the austenite finish temperature $\mathrm{T}_{\mathrm{Af}}$ were detected from the strain-temperature curve during thermal loading as the temperatures exhibiting $0.05 \%$ of residual strain.

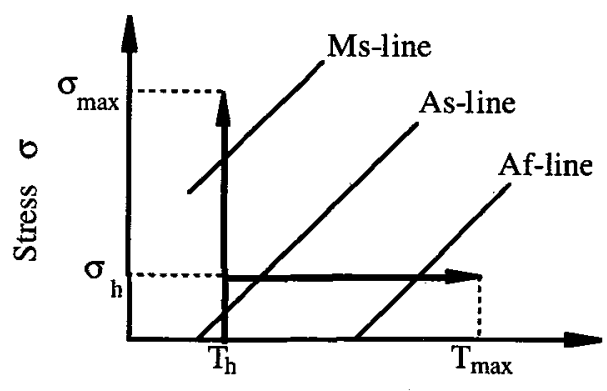

Temperature $\mathrm{T}$

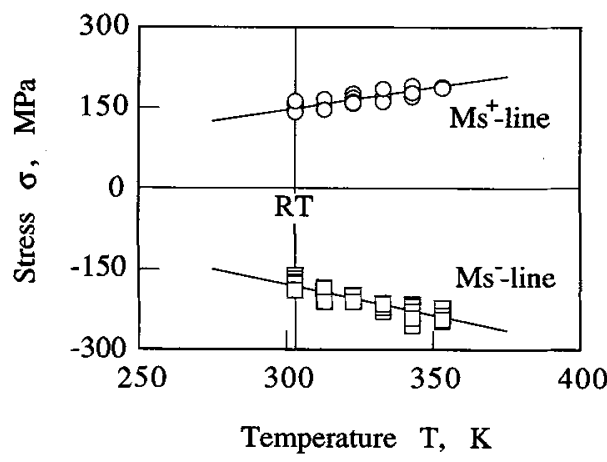

Figure 2: Martensite start lines.

Figure 1: Thermomechanical load path.

\section{MARTENSITE START LINES}

During isothermal loading in tension, the $\mathrm{M}^{+}$martensite is formed above the start stress $\sigma_{\mathrm{Ms}}^{+}$, whereas in isothermal compression the start stress $\sigma_{\mathrm{M}^{-}}$of the $\mathbf{M}^{-}$martensite is determined. Here, and henceforth, the superscripts " + " and "-" represent that the quantity corresponds to the tensile loading and the compressive loading, respectively. The $\mathrm{M}^{+}$martensite means here the variants formed when the specimen is loaded in tension, and the $\mathbf{M}^{-}$martensite the variants induced when the specimen is loaded in compression. The temperature-dependence of $\sigma_{\mathrm{Ms}}^{+}$and $\sigma_{\mathrm{Ms}}^{-}$represents the martensite start line in tension (Ms ${ }^{+}-$line) and in compression (Ms--line), respectively.

Figure 2 clearly shows that the martensite start stress depends linearly on the temperature both in tension and compression. The lines are asymmetric in tension and compression; The slopes of the $\mathrm{Ms}^{+}$-line and the $\mathrm{Ms}-$-line are $0.85 \mathrm{MPa} / \mathrm{K}$ and $-1.13 \mathrm{MPa} / \mathrm{K}$, respectively, and the martensite start stresses at RT are $\sigma_{\mathrm{Ms}}^{+}(\mathrm{RT})=142 \mathrm{MPa}$ in tension and $\sigma_{\mathrm{Ms}}^{-}(\mathrm{RT})=-182 \mathrm{MPa}$ in compression. The asymmetry of the transformation lines has also been observed in $\mathrm{NiTi}$ and $\mathrm{Cu}$-based shape memory alloys [24,25].

\section{AUSTENITE START/FINISH LINES AND INITIAL AUSTENITE LINE}

The austenite start line ( $\mathrm{As}^{+}-$line) and finish line $\left(\mathrm{Af}^{+}-\right.$line) are determined after the martensitic transformation in tension, which may be abbreviated by $\mathrm{P} \rightarrow \mathrm{M}^{+}$. The result, plotted in Fig.3, reveals that the austenite start line (hollow circles) and the finish line (solid circles) are almost parallel with a slope 1.9 $\mathrm{MPa} / \mathrm{K}$, being independent of $\sigma_{\max }^{+}$. The present data do not agree with such a speculation of Barrett and Sullivan [5] that the slope of the As-line depends on the extent of martensitic transformation during isothermal loading It should specially be noted that the lines can be extended to the compressive stress side 
without any change of the slope, as schematically been explained in the literature [12]. The effect of the prior martensitic transformation upon the austenite start and finish temperatures is also shown in the figure. The lower the maximum stress $\sigma_{\max }^{+}$, meaning the smaller the extent of the prior martensitic transformation or the smaller the amount of the $\mathrm{M}^{+}$martensite, the austenite start and finish lines approach to each other from both sides and the width of the reverse transformation zone becomes more narrow.

The austenite start temperature $\left(\mathrm{T}_{\mathrm{As}}^{-}\right)$and finish temperature $\left(\mathrm{T}_{\overline{\mathrm{Af}}}^{-}\right)$were also measured after the martensitic transformation in compression, $\mathrm{P} \rightarrow \mathrm{M}^{-}$. The results displayed in Fig.4 reveal just the same response given in Fig.3; the parallel austenite start lines (As--lines) and austenite finish lines (Af--lines), the increase in width of the transformation zone with the extent of prior martensitic transformation or with the amount of the $\mathrm{M}^{-}$martensite and the simple extension of the lines to the tensile side. The slope of the lines is about $-2.4 \mathrm{MPa} / \mathrm{K}$, being larger than that of the tensile case in Fig.3.

The martensite variants are formed upon pre-stressing, up to $\sigma_{\max }^{+}$or $\sigma_{\max }^{-}$, and a certain amount of strain energy, the amount of which depends on the extent of pre-stressing, is induced as a result of the accommodation of these variants. Such a crystallographic and thermomechanical state stays unchanged till the start of the reverse transformation, meaning the austenite start temperature is sensitive to the extent of pre-stressing. At around the end of the reverse transformation, however, the numbers and the morphology of the variants become almost the same, being independent of the extent of pre-stressing, due to an almost full progress of the reverse transformation. The effect of the pre-stressing on the transformation finish temperature is, therefore, small. The pre-stress dependence of $\mathrm{T}_{\mathrm{Af}}^{+}$and $\mathrm{T}_{\mathrm{Af}}^{-}$is attributed mainly to the local plastic slips induced in almost all cases, depending on the extent of pre-stressing.

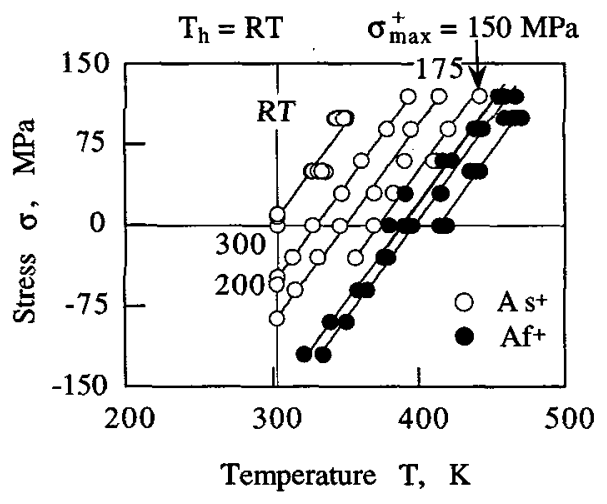

Figure 3: Austenite start/finish lines after martensitic transformation in tension.

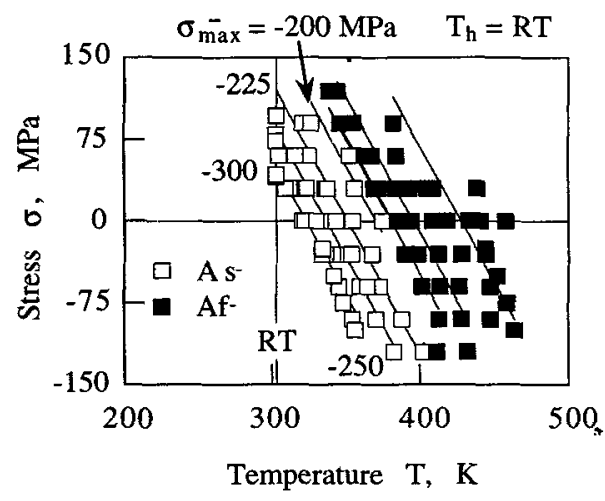

Figure 4: Austenite start/finish lines after martensitic transformation in compression.

The width of the reverse transformation zone decreases as the magnitude of applied stress becomes smaller. When the specimen is loaded at $\mathrm{T}_{h}=\mathrm{RT}$ just up to $\sigma_{\max }^{+}=142 \mathrm{MPa}$ or $\sigma_{\max }^{-}=-182 \mathrm{MPa}$, which corresponds to the martensite start stress in tension or in compression, respectively, the same austenite start temperature $\mathrm{T}_{\mathrm{As}}^{+}=\mathrm{T}_{\mathrm{As}}^{-}=375 \mathrm{~K}$ is observed in the subsequent heating under free-stress. The same is true for the austenite finish temperature, meaning $\mathrm{T}_{\mathrm{Af}}^{+}=\mathrm{T}_{\mathrm{Af}}^{-}=375 \mathrm{~K}$ under free-stress. The two lines, drawn from the point $(0 \mathrm{MPa}, 375 \mathrm{~K})$ parallel, respectively, to the $\mathrm{As}^{+} / \mathrm{Af}^{+}$lines and $\mathrm{As} / \mathrm{Af}$ lines, may be called the initial austenite lines (the initial $\mathrm{A}^{+}-$line and the initial $\mathrm{A}^{-}$-line in Fig.5). The initial A-lines, which represent a "degenerated" reverse transformation zone for the $\mathrm{M}^{+}$martensite or the $\mathrm{M}^{-}$martensite, correspond to the initial yield surface in the stress-temperature space in plasticity, which stands for an initial domain of the elastic response in the material. The subsequent yield surface changes its shape and position, starting from the initial yield surface, when the material is subjected to a further plastic deformation. Similarly, the initial A-lines, both the $\mathrm{A}^{+}$-line and the $\mathrm{A}^{-}$-line, spread into a reverse transformation zone bounded by the start and finish lines when the alloy experiences a martensitic transformation.

\section{UNIAXIAL THERMOMECHANICAL HYSTERESIS}

Figure 6 plots the thermomechanical hysteresis loops during successive tensile loading/unloading at RT and subsequent compressive loading/unloading at $\mathrm{RT}$, followed by heating/cooling under free-stress. It should be noted that, after being loaded up to $\sigma_{\max }^{+}$in tension which produces the stress-induced $\mathrm{M}^{+}$martensite in the specimen, the alloy has a reverse $M^{+} \rightarrow P$ transformation zone, at the start of the subsequent compressive loading. In the case of $\sigma_{\max }^{+}=150 \mathrm{MPa}$ the austenite finish stress $\sigma_{\mathrm{Af}}^{+}$is larger than the 
martensite start stress in compression $\sigma_{\mathrm{Ms}}^{-}$, meaning that the reverse $\mathrm{M}^{+} \rightarrow \mathrm{P}$ transformation zone and the $\mathrm{Ms}^{-}$-line are not overlapped at RT. The elastic compressive response is expected during loading from $\sigma_{A f}^{+}$ down to $\sigma_{\bar{M}}$, though the data reveals it in a very small part. This alloy response diminishes as $\sigma_{\max }$ becomes large since $\sigma_{\mathrm{Af}}^{+}$shifts down at RT with $\sigma_{\max }^{+}$, and finally in the case of $\sigma_{\max }^{+}=250 \mathrm{MPa}$ the $\mathrm{P} \rightarrow \mathrm{M}^{-}$transformation starts nearly at the same moment when the reverse $\mathrm{M}^{+} \rightarrow \mathrm{P}$ transformation finishes. The anomalous performance of the alloy indicated by an arrow in the figure is attributed to this metallurgical process. Since the reverse $\mathrm{M}^{+} \rightarrow \mathrm{P}$ transformation has already finished at $\sigma_{\max }^{+}=-300 \mathrm{MPa}$ for all three loading cases, the strain amplitude in the compressive branch is almost the same for all cases. So is the response during the subsequent thermal run.

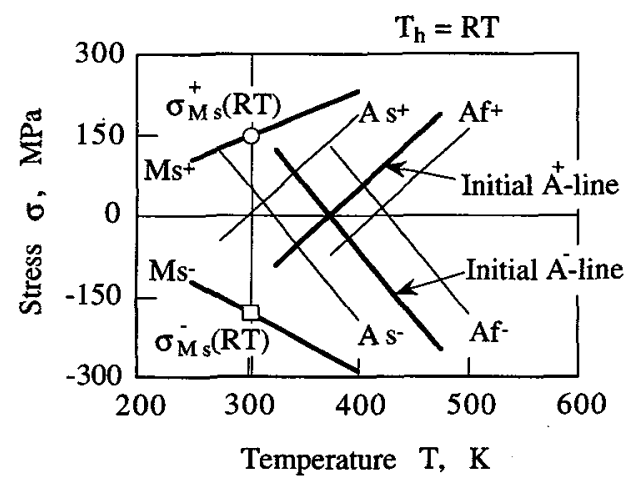

Figure 5: Transformation lines and reverse transformation zone.

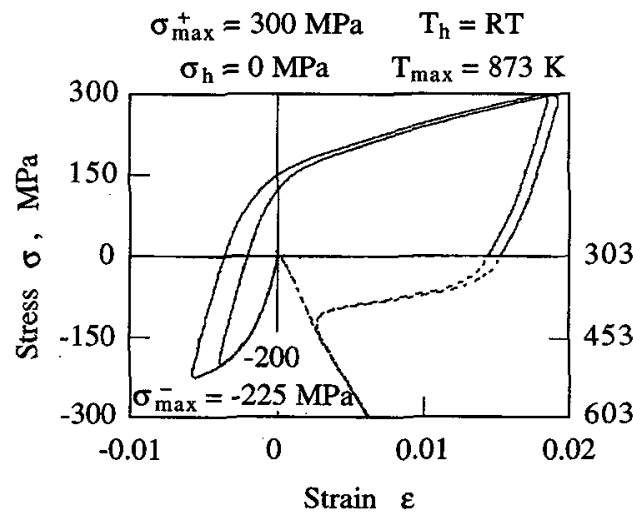

Figure 7: Thermomechanical hysteresis loops under compression/tension at $\mathrm{RT}$ and heating. Solid line: mechanical run, broken line: thermal run.

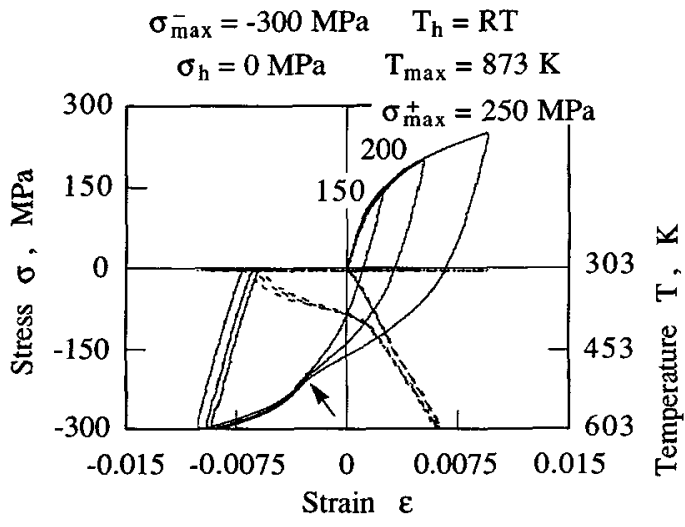

Figure 6: Thermomechanical hysteresis loops under tension/compression at RT and heating.

Solid line: mechanical run, broken line: thermal run.

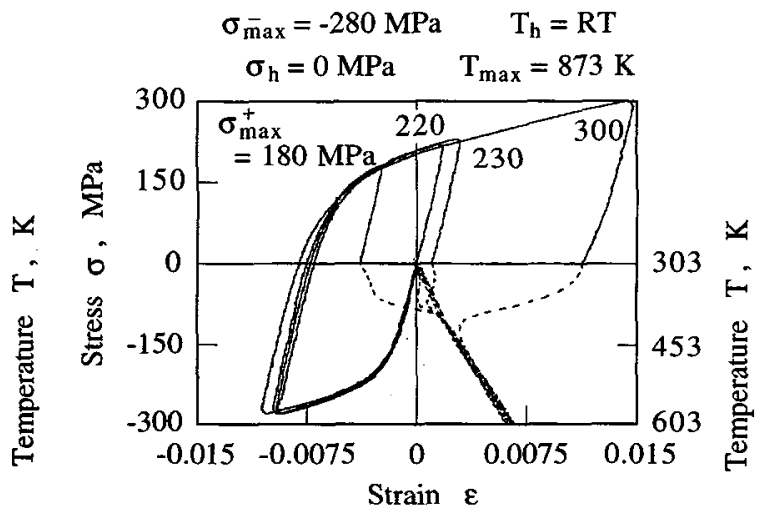

Figures 7 illustrates the alloy response when the specimen is firstly loaded in compression to produce the $\mathrm{M}^{-}$martensite and then reloaded in tension. Judging from the transformation diagram in Fig.4, the reverse $\mathrm{M}^{-} \rightarrow \mathrm{P}$ transformation and the $\mathrm{P} \rightarrow \mathrm{M}^{+}$transformation progress simultaneously during the tensile loading. The smooth response of the alloy is due to the fact that, contrary to the cases in Fig.6, the reverse transformation zone and the $\mathrm{M}^{+}$transformation zone almost overlap at RT.

In the process of mechanical loading the alloy is composed of the $\mathrm{M}^{-}$martensite, the $\mathrm{M}^{+}$martensite and the $\mathrm{P}$ phase, changing their fractions with the progress of loading. The situation is clearly proved by examining the strain recovery during the subsequent heating, shown in Fig.8. The specimen compressed 
down to $\sigma_{\max }^{-}=-280 \mathrm{MPa}$ is then loaded in tension up to the different values of $\sigma_{\max }^{+}$. After unloading, the specimen is subjected to the thermal run. The $\mathbf{M}^{-}$martensite produced during compressive loading is the cause of elongation of the specimen in the subsequent heating process. As $\sigma_{\max }^{+}$becomes larger, the amount of the $\mathbf{M}^{-}$martensite decreases due to the progress of the stress-induced reverse $\mathbf{M}^{-} \rightarrow P$ transformation in tension, resulting in the smaller amount of elongation during heating. If $\sigma_{\max }^{+}$is large enough, the $\mathrm{M}^{-}$martensite disappears in the specimen while mechanical loading in tension, whereas both the $\mathrm{M}^{+}$martensite and the $\mathrm{P}$ phase still remain. The $\mathrm{M}^{+}$martensite increases with $\sigma_{\max }^{+}$, inducing the larger amount of compression during heating. The experiment shows that no residual strain is observed after mechanical run of $\sigma_{\max }^{+}=220 \mathrm{MPa}$. The dilatation curve in the subsequent thermal run exhibits a compensation of the compressive deformation due to the $\mathrm{M}^{+}$martensite and the tensile deformation due to the $\mathrm{M}^{-}$martensite. These two deformations in the opposite direction compete during heating, and finally, when all the $\mathrm{M}^{+}$and $\mathrm{M}^{-}$martensites transform back to the $\mathrm{P}$ phase, the dilatation curve converges to the linear thermal expansion line.

\section{HYSTERESIS DURING CYCLIC THERMOMECHANICAL LOADING}

The untrained test specimen was subjected to 50 cycles of thermomechanical stress-controlled loading, one cycle of which was composed of an isothermal mechanical loading at the hold temperature $T_{h}=R T$ up to the maximum stress $\sigma_{\max }^{+}=350 \mathrm{MPa}$ and unloading down to the hold stress $\sigma_{\mathrm{h}}=0 \mathrm{MPa}$ and a subsequent heating under the hold stress $\sigma_{\mathrm{h}}$ up to $T_{\max }=873 \mathrm{~K}$ and cooling down to RT. Figure 9 shows the stress-strain-temperature hysteretic behavior during cycling. The hysteresis loops of the present alloy continue shifting to the higher strain side with keeping its shape unchanged, which is different from the data in $\mathrm{Ti}-\mathrm{Ni}$ and $\mathrm{Cu}$-based showing the convergence to a stationary limit loop.

The cyclic behavior was also investigated under the strain-controlled loading. Figure 10 plots the hysteresis loops for $\varepsilon_{\max }=3 \%$ at the number of cycles $N=1,10,20, \ldots, 100$. Like the results in the stress-controlled cycling, the residual strain is accumulated cycle by cycle since the transformation strain induced during mechanical loading is not fully recovered. This leads to the shift of hysteresis loop to the higher strain side. The evolution of the residual strain during cyclic loading suggests that there are two mechanisms of producing the residual strain; one of which works at the early stage of cycling under the large $\varepsilon_{\max }$. The other becomes dominant as the cycle progresses, and is active regardless of the magnitude of $\varepsilon_{\max }$.

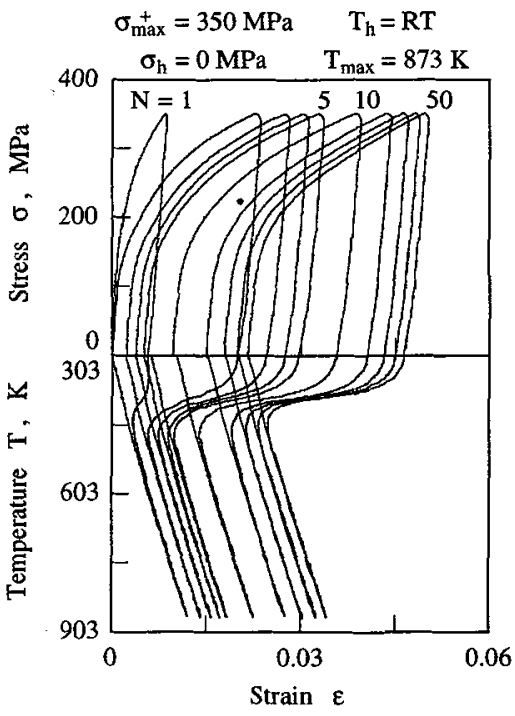

Figure 9: Stress-strain-temperature hysteresis; Tensile stress-controlled loading.

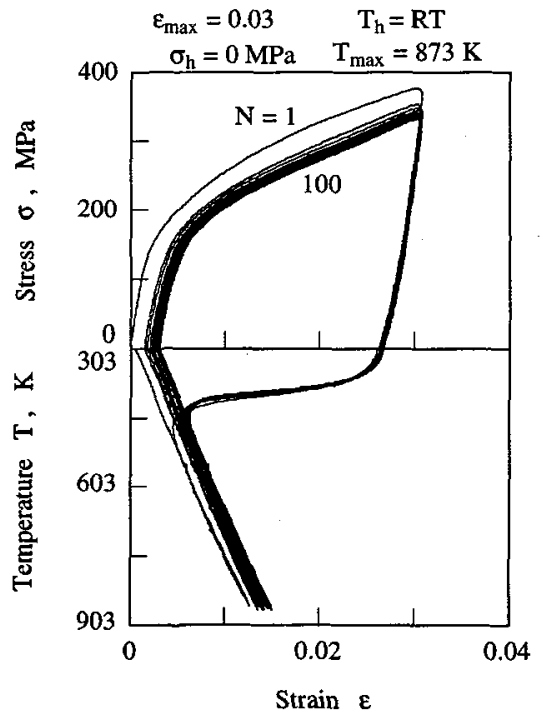

Figure 10: Stress-strain-temperature hysteresis; Strain-controlled loading.

Figure 11 shows the hysteretic behavior during alternating stress-controlled loading. The specimen was first mechanically loaded at RT up to the maximum tensile stress $\sigma_{\max }^{+}=350 \mathrm{MPa}$ and unloaded down to the stress-free state. After heating/cooling under free-stress between the maximum temperature $\mathrm{T}_{\max }=$ $873 \mathrm{~K}$ and RT, the isothermal compression was carried out at RT down to the maximum compressive stress 
$\sigma_{\max }^{-}=-350 \mathrm{MPa}$. The unloading was followed by the heating under free-stress up to $\mathrm{T}_{\max }=873 \mathrm{~K}$ and the subsequent cooling down to RT. The martensite phase is induced in tension at the odd-numbered cycles, and in compression at the even-numbered cycles. A compressive residual strain is produced at the second cycle. From then on the hysteresis loops shift to the higher strain side cycle by cycle. The crowded hystereses illustrated in Fig.11 stem from a little change in the residual strain (cf. Fig.12).

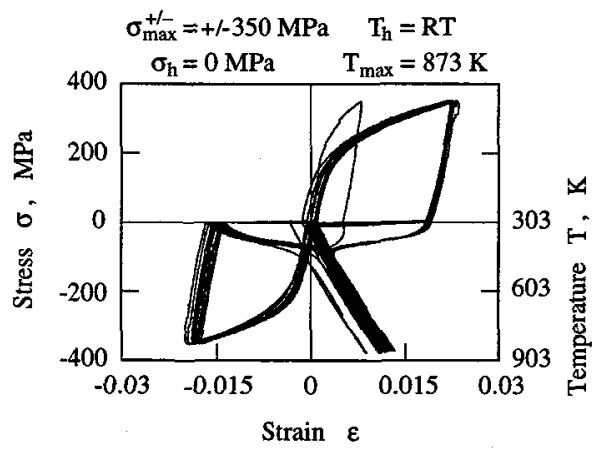

Figure 11: Stress-strain-temperature hysteresis; Alternating stress-controlled loading.

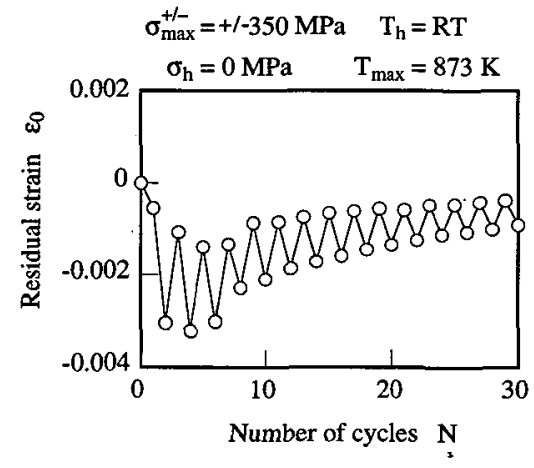

Figure 12: Evolution of residual strain.

\section{Acknowledgments}

Part of this work was financially supported by the Special Research Fund/ Tokyo Metropolitan Government. The supply of the alloy materials by the Steel Research Center/ NKK Co. is acknowledged.

\section{References}

[1] Sun Q.P., Hwang K.C., J. Mech. Phys. Solids 41 (1993) 1.

[2] Patoor E., Eberhardt A., Berveiller M., Mechanics of Phase Transformations and Shape Memory Alloys, AMD-Vol.189/PVP-Vol.292, L.C.Brinson and B.Moran Eds. (ASME, 1994) 23.

[3] Tanaka K., Oberaigner E.R., Fischer F.D., Mechanics of Phase Transformations and Shape Memory Alloys, AMD-Vol.189/PVP-Vol.292, L.C.Brinson and B.Moran Eds. (ASME, 1994) 151.

[4] Levitas V.I., Int. J. Engng Sci. 33 (1995) 921.

[5] Barrett D.J., Sullivan B.J., J. Intell. Material Syst. Struct. 6 (1995) 831.

[6] Funakubo H. Ed., Shape Memory Alloys (Gordon and Breach Science Publ., New York 1987).

[7] Tanaka K., Hayashi T., Fischer,F.D., Buchmayr B., Z. Metallkd. 85 (1994) 122.

[8] Tanaka K., Nishimura F., Tobushi H., Z. Metallkd. 86 (1995) 211.

[9] Tanaka K., Nishimura F., Tobushi H., Mech. Materials 19 (1995) 271.

[10] Tanaka K., Nishimura F., Tobushi H., J. Physique IV 5-2 (1995) 477.

[11] Wayman C.M., Duerig T.W., Engineering Aspects of Shape Memory Alloys, T.D.Duerig, K.N.Melton, D.Stöckel and C.M.Wayman Eds. (Butterworth-Heinemann, London, 1990) 3.

[12] Barrett D.J., J. Intell. Materials Syst. Struct. 6 (1995) 329.

[13] Bekker A., Brinson L.C., Mechanics of Phase Transformations and Shape Memory Alloys, AMD-Vol.189/PVP-Vol.292, L.C.Brinson and B.Moran Eds. (ASME, 1994) 195.

[14] Paskal Yu.I., Monasevich L.A., Phys. Met. Metallogr. 53 (1981) 95.

[15] Müller I., Xu H., Acta Metall. Mater. 39 (1991) 263.

[16] Amengual A., Cesari E., Seguí C., Proc. ICOMAT 92, C.M.Wayman and J.Perkins Eds. (Monterey Institute for Advanced Studies, Carmel, 1993) 377.

[17] Wei Z., Yang D., Scr. Metall. 22 (1988) 1245.

[18] Robinson J.S., McCormick P.G., Mater. Sci. Forum 56-58 (1990) 649.

[19] Tan S., Yang S., Scr. Metall. Mater. 27 (1992) 229.

[20] Sittner P., Tokuda M., J. Physique IV 5-8 (1995) 1003.

[21] Tokuda M., Sittner P., Takakura M, Men Y., Materials Sci. Research Int. 1 (1995) 260.

[22] Nishimura F., Watanabe N., Tanaka K., Materials Sci. Engng A 221 (1996) 134.

[23] Nishimura F., Watanabe N., Tanaka K., Materials Sci. Research Int. 3 (1997) 23.

[24] Vacher P., Lexcellent C., Mechanical Behaviour of Materials - VI, Vol.3, M.Jono and T.Inoue Eds. (Pergamon Press, Oxford, 1991) 231.

[25] Orgéas L., Favier D., J. Physique IV 5-8 (1995) 605. 